\title{
The Comparative Study of Image Exaggeration in Old and New Iranian and Foreign Advertisement Based on Semiology
}

\author{
'Seyyedeh Fatemeh Hosseini, ${ }^{2}$ Setareh Majidi \\ ${ }^{1}$ M.A graduate student in linguistics, central Tehran branch, Islamic Azad University, Tehran, Iran \\ ${ }^{2}$ Assistant professor of linguistics department, central Tehran branch, Islamic Azad University, Tehran, Iran \\ ABSTRACT
}

This article has studied the image exaggeration in Iranian and foreign advertisement based on semiology. This study included articles and books that were written about semiotics, advertisements, and also exaggeration.

\begin{abstract}
"According to study results, while old and new Iranian and foreign advertisement has differed in latest decades, all of them have used exaggeration but in other way. In addition, there is relation between scientific use of exaggeration and modern societies.
\end{abstract}

\section{Keywords}

Advertisement; sign; exaggeration; text; non-text.

\section{INTRODUCTION}

Today, living in modern societies contains advertising messages. These messages in the numerous and diverse form affected people's lives. Therefore; today more than ever, we are dealing with advertising. Familiar with ads and its components, by comparing and identifying the strength and weakness of ads can be an important factor in development. Exaggeration is a form of written and visual advertising that have been less analyzed, Therefore; the aim of this research is identifying and comparing signs such as, the exaggeration which is used in Iranian and foreign advertisement.

This research is descriptive-analytic and data has been collected in library. For this purpose, 96 samples of Iranian and foreign advertisements in latest decades have been chosen which some of them have been analyzed. The theoretical framework is from the perspective of" Roland Barthes". Now there are some questions; the first question specifies difference between Iranian and foreign advertisement in latest decades. The second specifies use of exaggeration in ads and specifies difference of exaggeration in Iranian and foreign ads.In addition, the last identifies the relation between scientific uses of exaggeration and other signs with modern society.

\section{Review of the Relevant Studies}

\section{Barthes Model}

As Roland Barthes noted, Saussure's model of the sign focused on denotation at the expense of connotation was left to subsequent theorists (notably Barthes himself) to offer an account of this important dimension of meaning (Barthes 1967, 89ff).

Barthes initially argued that a codecould be identified only at a level higher than the 'literal' level of denotation. In 1973 , Barthes had shifted his ground on this issue. In analyzing the realist literary text, Barthes came to the conclusion that 'denotation is not the first meaning, but pretends to be so; under this illusion, it is ultimately no more than the last connotations (the one which seems both to establish and close the reading), the superior myth by which the text pretends to return to the nature of language (Barthes 1974, 9).

\section{Advertisement}

Advertisement is how a company encourages people to buy their products, services or ideas. An advertisement (or "ad" for short) is anything that draws good attention towards these things. It is usually designed by an advertising agency for an identified sponsor, and performed through a variety of media. Ads appear on television, as well as radio, newspapers, magazines and as billboards in streets and cities. They try to get people to buy their products, products by showing them the positive points rather than the negative points of their products.

(TheFreeDictionary.com).

\section{Semiotics}

Meanings between consumers and marketers depict signs and symbols that are encoded in everyday objects (Devid Glen, 1986,196). Semiotics is the study of signs and how they are interpreted. Advertising has many hidden signs and meanings Within brand names, logos, package designs, print advertisements, and television advertisements. Semiotics aims to study and interpret the message being conveyed in (for example) advertisements. Logos and advertisements can be interpreted at two levels - known as the surface level and the underlying level. The surface level uses signs creatively to create an image or personality for a product. These signs can be images, words, fonts, colors, or slogans. The underlying level is made up of hidden meanings. The combination of images, words, colors, and slogans must be interpreted by the audience or consumer (Beasley, 2002). The "key to advertising analysis" is the signifier and the signified. The signifier is the object and the signified is the mental concept. (Pinson, 1998) A product has a signifier and a 
signified. The signifier is the color, brand name, logo design, and technology. The signified has two meanings known as denotative and connotative. The denotative meaning is the meaning of the product.

\section{Exaggeration}

To consider, represent, or cause to appear as larger, more important, or more extreme than is actually the case; over state (www.thefreedictionary.com).

Even if, at ad is cursive level we are dealing only with the text image couple, the broad spectrum of organizational forms of the rhetorical figures in advertisements, such as using hyperboles, is based mainly on the great availability/flexibility of each component to express its contents in diverse forms. Even when the lexical level is concerned, the advertising discourse seems not to be bound by any rules. Its openness toward increasingly more varied categories of terms, its propensity towards polysemy, insinuation and reading between the lines make advertising a contemporary discourse of great originality and dynamism. Moreover, those which linguists call deviations from the rules of language (meta-plastic or onomatopoeic changes of words) have come to be seen as distinctive traits of this kind of discourse. The exaggeration of the size (Extra Big hamburger), the adding of sounds (Mirindaaaaa!, Bambuchaaa!), using onomatopoeic formations (Galina Blanca, bul-bul!, HeiPsstCichiCichi, KltzPmzAahh!), replacing sounds or mixing words (Méganemaipomenit = Mégane +nemaipomenit - catchphrase in the Romanian commercial for Renault Megane, a mix between the name of the product and the word nemai pomenit - en. amazing), are common place techniques for generating the advertising characteristic fervent discourse.(kleitch,2015,178)

\section{Data Analysis}

\section{Image Exaggeration in Old Iranian Advertisement}
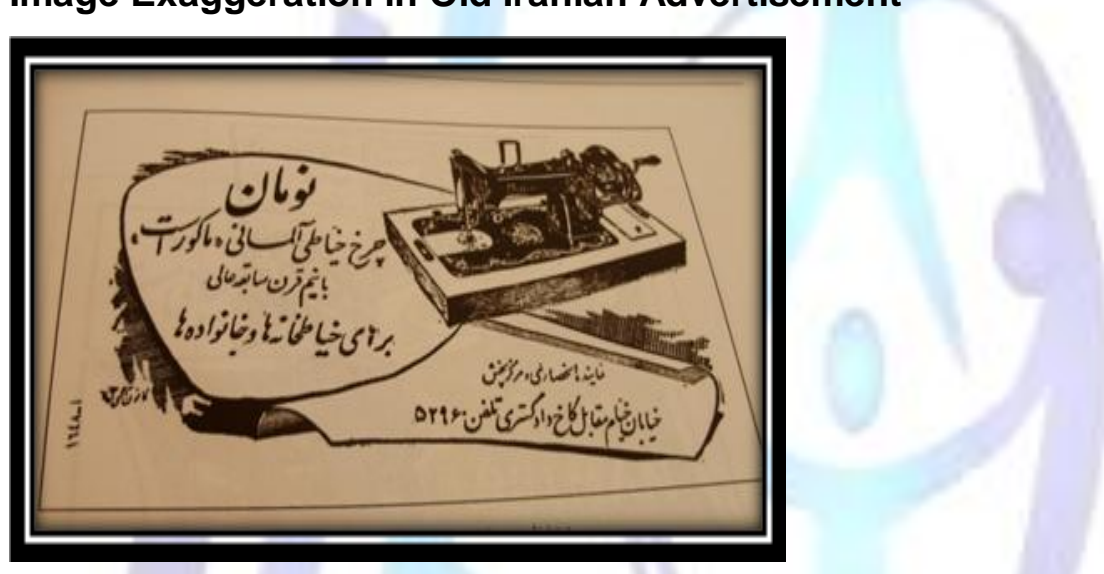

In the above image analysis the first layer of text and message to be seen, "Neumann is a German sewing machine" "Makur", this is dependent to German. Germany has connotations for Iranian consumer. Common cultural and commercial fields between Germany and Iran, the same race, powerful industry and etc., all of them can attract the German word for Iranian consumer. This picture is black and white; concentration is more on the words.

Image of the sewing machine on the right is simple and far from any technique." Neumann" logo with the main headline, different patterns of written text of ads, length of sentence, type of segmentation, font size and font type, can be element of paradigmatic in ads text. Two types of exaggeration are at this ad, the visual and the verbal. At the right, image of the sewing machine which is separated and bowed from environment, tries to the impressive. At the left top of box, the word of Neumann is exaggerated by size and dark color.

\section{Image Exaggeration in New Iranian Advertisement}

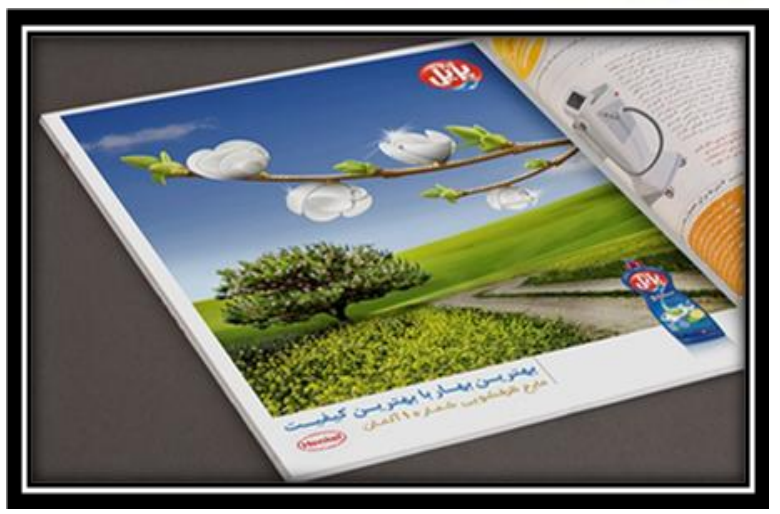

This image is an Iranian ad 90s and is related to Pril dishwashing liquid. According to Roland Barthes at first what needs to pay attention is ad text. In the upper right corner, pril the word is written in the circular and in line with the word of pril on 
the dish washing. It means pril is carved on the nature. Pril logo in the nature has paradigm and connotation which shows pril is compatible with nature. Bolding pril is exaggerated here.

The slogan that is written below of the image "Best Spring with best quality" has multi-purpose and connotation. This sentence, that is relatively written large with a blue color, indicates best quality and spring will come with pril. We can see this similarity with blue box of dishwashing liquid with blue sky. "German number 1 dish washing liquid and Henkel" emphasizes on power and credibility of Germany for Iranian consumer.

In the image and non-text elements, we see nice feature of the nature that pril dish washing brought clean and shine blossom. The blossoms are mixture of dishes such as; (cups, saucer and teapot) that all of these elements reminiscent spring comes with pril. Green nature and blue sky can be seen in the text and the image. Pril liquid is at the beginning of the safe road, but twisty. Color of the pril is like the nature. Red circle of pril logo with Henkel color aligned and support each other. Everything is exaggeratedly clean by pril that even identify dishes to be blossom on the tree which is very difficult.

\section{Image Exaggeration in Old Foreign Advertisement}

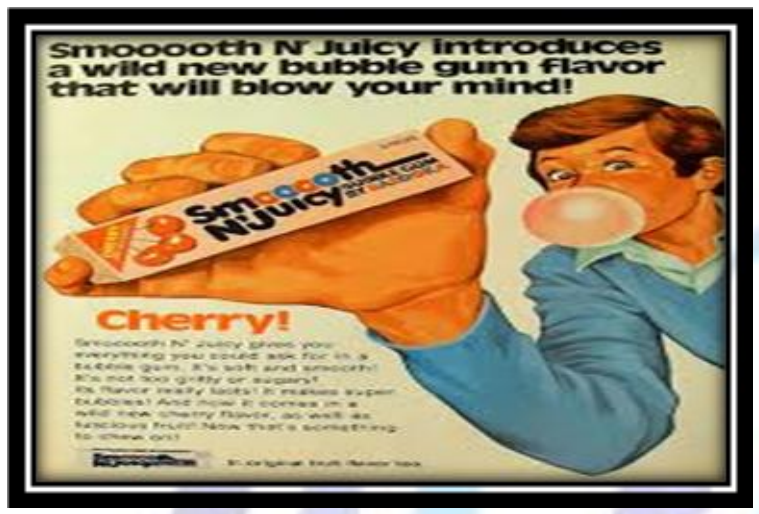

The image is related to a chewing gum ad in the 1970s. According to Barthes in this picture, firstly, the text must be examined: on top of the image, Smooooth $\mathrm{N}$ Juicy is written bold and black «introduces a wild new bubble gum flavor that will blow your mind». Name of product is Smooth $\mathrm{N}$ juicy and the picture is clear as a gum cherry flavor.

Exaggerating techniques is been being used for taking attention on the words, Adding sound of (000) is kind of exaggeration, that o letter is associated with bubble gum, and shows the state of bubble. What is more important is the emphasis on the bubble of chewing gum, and coloring of the o letter shows different flavor of the gum.

The text at the top of the page is the same with the text box. The word Cherry is located in the bottom right of cherry photo, which introduces real taste of cheery in the gum. For more emphasize, it has been used the same color.

Non text elements, is an Image of a boy with surprised eyes that blows a big chewing gum, with his hand held the box of gum. His hand is larger than his body which shows the image exaggeration techniques.

What's on the box, including the text and color, is used exactly on the picture. Text and visual elements are paradigmatic for each other.

\section{Image Exaggeration in New Foreign Advertisement}

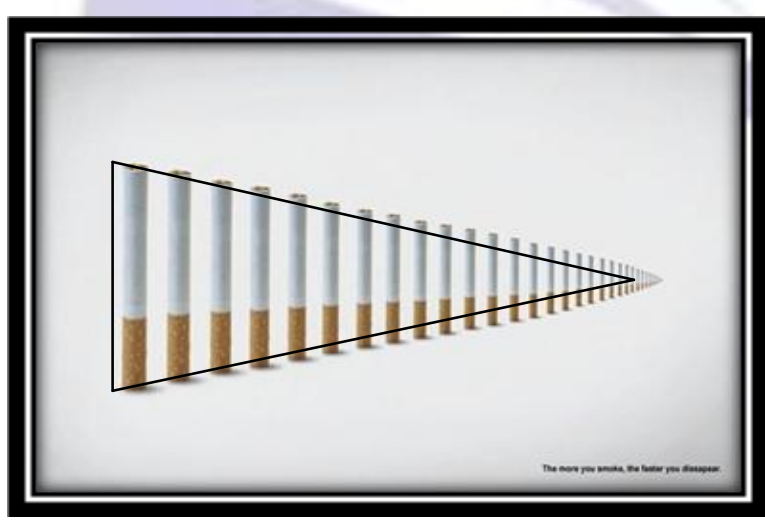

This advertising is relevant to the 2000 s, what we see as a text is one sentence that we can hardly read it, "The more you smoke, the faster you disappear."

Here we are dealing with a real sentence and advice .the sentence as well as the meaning is written by small and faded font, which is just for exaggeration. 
We see in the image gray background that cigarettes are lined like poles .first, they are big but as much as their number increases, they fade out of sight. The meaning of the text is in line with image that shows danger of smoking.

On the other hand, and with a deeper look we find new cut of the picture (which I have marked with arrows). Set cigarettes have formed a triangle that head of triangle is much closed to the end; this ending shows cold and smoky fate.

Table 1: Abundance ratio of the studied advertisement by exaggeration

\section{Conclusion}

\begin{tabular}{|l|c|c|c|c|}
\hline $\begin{array}{c}\text { type of } \\
\text { ads }\end{array}$ & $\begin{array}{c}\text { Total } \\
\text { number }\end{array}$ & $\begin{array}{c}\text { Number of } \\
\text { exaggeration }\end{array}$ & simple & advanced \\
\hline $\begin{array}{l}\text { Old } \\
\text { Iranian }\end{array}$ & 29 & 23 & 25 & 4 \\
\hline $\begin{array}{l}\text { New } \\
\text { Iranian }\end{array}$ & 20 & 18 & 10 & 10 \\
\hline $\begin{array}{l}\text { Old } \\
\text { foreign }\end{array}$ & 23 & 22 & 11 & 12 \\
\hline $\begin{array}{l}\text { New } \\
\text { foreign }\end{array}$ & 24 & 24 & 3 & 21 \\
\hline
\end{tabular}

These results were obtained after studying: Old Iranian ads used bold letter and bold type, little by little, enlargement of the image added. In new period, by development of science and graphic, concentration is more on the image and exaggeration, but it needs to be evaluated scientifically. Old foreign ads were colored; they knew most kind of exaggeration and have used it very good. Focus was on the image and exaggeration. In new era, In addition to using the technique and science, ads are more conceptual and their base is on the concepts. And we can say there is relation between scientific use of exaggeration and a society that moves toward progress and modernity.

\section{REFERENCES}

[1] "Advertize - Define Advertize at Dictionary.com". Dictionary.com. Retrieved September 8, 2015.

[2] Barthes, Roland ([1964] 1967). Elements of Semiology (trans. Annette Lavers \& Colin Smith). London: Jonathan Cape.

[3] Barthes, Roland ([1973] 1974): S/Z. London: Cape.

[4] Beasley, Ron (2002). Persuasive Signs: The Semiotics of Advertising. Berlin, Germany: Walter de Gruyter GmbH \& KG.

[5] kleitsch, Barbu, 2015, Use of Hyperboles in Advertising Effectiveness, Romania, West University of Timisoara.

[6] Mick, Devid Glen (September 1986). "Consumer Research and Semiotics: Exploring the Morphology of Signs, Symbols, and Significance". The Journal of Consumer Research 13 (2): 196.

[7] Pinson, Christian (1998), Marketing Semiotics (PDF).

\section{Author' biography with Photo}

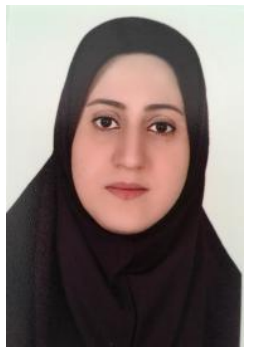

Seyyedeh Fatemeh Hosseini , M.A Linguistics graduate student of Islamic Azad University, Central Tehran Branch, Department of Foreign Languages. Email:hosseinif647@gmail.com

EDUCATION

- 13/02/2013-13/02/2016 Master's Degree - General Linguistics - Islamic Azad University of Central Tehran Branch, Faculty of Foreign Language, Tehran, Iran

-14/02/2006-01/07/2009 Bachelor's Degree - English Translation - Islamic Azad University

of Qom, Iran 